\title{
IMPACTO DAS VARIÁVEIS AMBIENTAIS EM INCUBATÓRIO DE ESTÁGIO MÚLTIPLO DE FRANGOS DE CORTE
}

\author{
MARTA S. BARACHO ${ }^{1}$, IRENILZA DE A. NÄ̈̈S ${ }^{2}$, ANA C. S. GIGLI ${ }^{3}$
}

\begin{abstract}
RESUMO: Este trabalho visou a quantificar as características de resposta produtiva de pintos de corte provenientes de duas linhagens comerciais, em incubatório de regime de estágio múltiplo. Para tal, foram monitorados três lotes de ovos férteis em incubatório comercial, verificando o impacto das seguintes variáveis ambientais: temperatura, velocidade do ar, umidade relativa, concentração de dióxido de carbono e presença de fungos. $\mathrm{O}$ acompanhamento de pintos provenientes de duas linhagens comerciais distintas $\left(\mathrm{Cobb}^{\circledR}\right.$ e Avian $\left.{ }^{\circledR}\right)$ foi feito em três lotes, quando também foram coletados dados de perdas. A análise de componentes principais foi empregada para associar as variáveis de ambiente, produção e perdas, observando a magnitude dos vetores. Os resultados mostraram que o ambiente de incubação influenciou diretamente no desempenho (qualidade, incidência de anormalidades e mortalidade) das duas linhagens de frango de corte. Ambas as linhagens apresentaram perdas produtivas relacionadas à baixa temperatura de incubação na incubadora e no nascedouro, mostrando que a temperatura de incubação é o fator mais importante para que sejam alcançados índices produtivos ótimos.
\end{abstract}

PALAVRAS-CHAVE: avicultura, incubação, ambiência.

\section{IMPACT OF ENVIRONMENTAL VARIABLES IN MULTI SETTER INCUBATION IN BROILER'S PRODUCTION}

\begin{abstract}
This research aimed to quantify the characteristics of the productive response of pullets from two distinct genetic strains in multi setter incubator. For this three batches of fertile eggs were monitored in a commercial incubator verifying the impact of the following environmental variables: temperature, air velocity, relative humidity, carbon dioxide concentration and presence of fungi. The follow up was done in three flocks of broiler pullets from two commercial genetic strains $\left(\mathrm{Cobb}^{\circledR}\right.$ and Avian $\left.{ }^{\circledR}\right)$ also along with the data of losses. The principal components analysis was used for associating the variables of environment, production and losses by observing the magnitude of the vectors. Results showed that the environment of incubation influenced the performance (quality, incidence of abnormalities and mortality) of the two broiler's strains. Both strains presented productive losses related to low temperature inside the incubator and in the hatchery showing that incubation temperature is the most important factor for reaching ideal productive index.
\end{abstract}

KEYWORDS: poultry, incubation, environment.

\section{INTRODUÇÃO}

O incubatório é um ambiente estratégico da produção avícola e está fortemente vinculado à granja de matrizes (GONZALES, 2003). A principal meta do incubatório é transformar biologicamente ovos férteis em pintos de um dia no volume, prazo e qualidade desejados, minimizando a incidência de anormalidades e contaminação, de forma a atender às necessidades e expectativas da produção avícola, ao menor custo (BIEZUS, 2001; TONA et al., 2003).

Segundo CALIL (2007), por muito tempo, a incubação foi reconhecida apenas como uma área necessária da cadeia produtiva avícola. Atualmente, este conceito do processo está modificando-se,

\footnotetext{
${ }^{1}$ Bióloga, Pesquisadora Colaboradora, FEAGRI-UNICAMP, Campinas - SP, baracho@ feagri.unicamp.br.

${ }^{2}$ Eng $^{\mathrm{a}}$ Civil, Professora Colaboradora, FEAGRI-UNICAMP, Campinas - SP, irenilza@ agr.unicamp.br.

${ }^{3}$ Bióloga, FEAGRI-UNICAMP, Campinas - SP.

Recebido pelo Conselho Editorial em: 25-9-2008

Aprovado pelo Conselho Editorial em: 11-5-2010
} 
uma vez que o conhecimento gerado em áreas como nutrição, sanidade, manejo e ambiência, desenvolveu-se em um ritmo acentuado, entretanto não foi acompanhado pela tecnologia de incubação nos últimos anos. Dentro do contexto da incubação moderna, apenas recentemente foi reconhecido que fatores relacionados à incubação influenciam no desempenho e no crescimento de frangos de corte (DECUYERE et al., 2001; TONA et al., 2003). Portanto, é importante que o ambiente do incubatório tenha gerenciamento e manejo adequados e que seja homogêneo em todas as suas áreas, uma vez que a produtividade, assim como a qualidade do produto final, pode depender destas variáveis (DECUYPERE \& MICHELS, 1992).

A temperatura ideal de incubação é normalmente definida como a temperatura em que se pode alcançar o máximo de eclodibilidade (FRENCH, 1997). A maioria das espécies de aves possui uma temperatura ótima de incubação em torno de 37 a $38^{\circ} \mathrm{C}$, e pequenos desvios deste valor possuem impacto no sucesso da incubação e no desenvolvimento embrionário (WILSON, 1991). Para GUSTIN (2003), variações de $\pm 1^{\circ} \mathrm{C}$ provocam grande impacto nos resultados, dilatando o período de nascimento, ocasionando retardo no desenvolvimento embrionário e diminuição do ritmo de batimento cardíaco, com atraso de nascimento, má formação e umbigo não cicatrizado. Por outro lado, o autor reporta que temperaturas altas promovem aceleração no desenvolvimento do embrião com má posição embrionária, pouca plumagem, bicagem e nascimentos adiantados. Segundo WILSON (1991), as incubadoras artificiais devem ser projetadas para assegurar o controle acurado de temperatura no interior da máquina. Desse modo, a temperatura do embrião em desenvolvimento não se desviará dos valores preconizados.

O processo produtivo do incubatório é constituído de entradas (ovos incubáveis) e da transformação biológica dessas entradas em produtos (pintos de um dia), agregando valores (GUSTIN, 2003). O sucesso da incubação envolve condições ótimas de manejo, considerando as condições impostas pelo ambiente de criação, somatório dos fatores biológicos (nível de estresse, equilíbrio eletrolítico, termorregulação e preservação do pinto pós-nascido) e fatores físicos (tempo e clima). As necessidades ambientais são muito específicas e devem ser ideais para sustentar o desenvolvimento embrionário devido à necessidade de manutenção de padrões de eclosão de diferentes linhagens de frangos de corte existentes atualmente (BOLELI, 2003; MURAROLI \& MENDES, 2003; BOERJAN, 2006).

BRAMWELL (2002) reporta que os parâmetros de qualidade de eclosão têm aumentado, destacando quatro pontos principais relacionados às perdas que ocorrem na produção, quais sejam: a fertilidade dos ovos, as condições de incubação, o manejo do incubatório e a qualidade da casca do ovo.

Considerando que a avicultura brasileira é carente de informação sobre este tema, que se constitui em importante custo econômico na cadeia de produção avícola (ROSA \& ÁVILA, 2000), este trabalho visou a quantificar as características de resposta (qualidade, incidência de anormalidades e mortalidade) de ovos férteis incubados em regime de estágio múltiplo, e posterior nascimento de pintos de corte, provenientes de duas linhagens comerciais.

\section{MATERIAL E MÉTODOS}

A coleta de dados deu-se em um incubatório comercial localizado a uma longitude de $46^{\circ} 46^{\prime} 25^{\prime}$ ' W, latitude de $22^{\circ} 43^{\prime} 17^{\prime}$ ' $\mathrm{S}$ e altitude de $683 \mathrm{~m}$. Os experimentos foram conduzidos nas salas do incubatório, em que são utilizadas onze máquinas de incubação do modelo CASP CMg 125 R/e, tipo corredor, com estágio múltiplo de incubação (Tabela 1). A sala de nascedouro usada possuía seis nascedouros do modelo CASP G $21 \mathrm{HR} / \mathrm{e}$ (Tabela 2). O controle de temperatura de bulbo seco é do tipo on/off com histerese. O sensor de temperatura é construído para operar na faixa de 21,1 a $43,3^{\circ} \mathrm{C}\left(70\right.$ a $\left.110^{\circ} \mathrm{F}\right)$ e é calibrado pelo sistema através de um termostato de calibração de alta precisão.

Os dados de ambiente (temperatura de bulbo seco, T; umidade relativa do ar, UR; velocidade do ar, VA) foram registrados utilizando os seguintes equipamentos: termo-higroanemômetros 
Modelo HTA 4200 PACER $^{\circledR}$ para coleta de dados referentes a T, UR e VA. O equipamento tinha capacidade de armazenamento para 1.000 registros (UR, \%; T, ${ }^{\circ} \mathrm{C} ; \mathrm{VA}, \mathrm{m} \mathrm{s}^{-1}$ ).

TABELA 1. Dimensões da incubadora CASP CMg $125 \mathrm{R} / \mathrm{e}$. Incubator CASP MC 125 R/e dimensions.

\begin{tabular}{|c|c|}
\hline Dados & Dimensão \\
\hline Frente $(\mathrm{m})$ & 3,45 \\
\hline Lateral (m) & 6,97 \\
\hline Altura (m) & 2,67 \\
\hline Área $\left(\mathrm{m}^{2}\right)$ & 24,05 \\
\hline Volume $\left(\mathrm{m}^{3}\right)$ & 64,21 \\
\hline Número de gavetas & 1.296 \\
\hline Ovos por gaveta & 96 \\
\hline Capacidade nominal (ovos) & 124.416 \\
\hline Água $\left(\mathrm{L} \mathrm{h}^{-1}\right)$ & 30 \\
\hline Pressão de entrada no regulador (psi) & 70 \\
\hline Vazão de ar para refrigeração $\left(\mathrm{m}^{3} \mathrm{~h}^{-1}\right)$ & 2.300 \\
\hline
\end{tabular}

TABELA 2. Dimensões do nascedouro CASP G $21 \mathrm{HR} / \mathrm{e}$. Birthplace CASP G21 HR/e dimensions.

\begin{tabular}{|c|c|}
\hline Dados & Dimensão \\
\hline$\overline{\text { Frente }(\mathrm{m})}$ & 2,93 \\
\hline Lateral (m) & 2,76 \\
\hline Altura (m) & 2,31 \\
\hline Área $\left(\mathrm{m}^{2}\right)$ & 8,09 \\
\hline Volume $\left(\mathrm{m}^{3}\right)$ & 18,68 \\
\hline Número de gavetas & 216 \\
\hline Ovos por Gaveta & 96 \\
\hline Capacidade nominal (ovos) & 20.736 \\
\hline Número de suportes & 4 \\
\hline Ovos para suporte & 5.184 \\
\hline Água $\left(\mathrm{L} \mathrm{h}^{-1}\right)$ & 30 \\
\hline Pressão de entrada no regulador (psi) & 70 \\
\hline Umidade $\quad$ ar $\left(\mathrm{L} \mathrm{h}^{-1}\right)$ & 2.100 \\
\hline Vazão de água para serpentina $\left(\mathrm{m}^{3} \mathrm{~h}^{-1}\right)$ & 300 \\
\hline
\end{tabular}

Para a avaliação da concentração de $\mathrm{CO}_{2}$, foram coletadas amostras de ar instantâneas a 1,0 m de altura do piso, no centro geométrico do ambiente, utilizando uma bomba de sucção e tubos calorimétricos Dräger® para detecção de $\mathrm{CO}_{2}$ (100 - 3.000 ppm).

A coleta de fungos no ar foi feita por gravimetria, de acordo com a metodologia de exposição de placas de Petri (10 cm de diâmetro) contendo meio de cultura completo (PONTECORVO et al., 1953), permitindo o crescimento dos esporos de fungos dispersos pelo ar contidos na incubadora e no nascedouro, e na sala de vacinação. Visando a obter uma amostragem homogênea durante o acompanhamento dos lotes, a exposição de placas de Petri foi realizada após o manejo de limpeza das salas e das máquinas de incubação, no período da manhã. Cada amostragem teve duração de 15 min, e foram utilizadas duas placas de Petri (amostragem em duplicatas) para cada local. Após a exposição de placas de Petri nos locais determinados para coleta de fungos, as amostras foram levadas ao laboratório e incubadas por três dias em estufa, a uma temperatura de $27{ }^{\circ} \mathrm{C}$, e o número de unidades formadoras de colônias (UFC) de fungos foi contado após esse período. 
Os equipamentos e as placas de Petri foram alocados nos centros geométricos do interior das máquinas de incubação, sala de incubadora, sala de nascedouro e sala de vacinação, enquanto a coleta dos dados foi organizada conforme indicado na Tabela 3.

Os dados de índices zootécnicos foram fornecidos pela administração do incubatório, ao final de cada lote de produção analisado, estando relacionados à eclosão de pintos de um dia de primeira qualidade, de segunda qualidade, mortalidade e refugagem (eliminados).

Os ovos férteis selecionados neste estudo foram provenientes de matrizes pesadas com 36 semanas de idade e de duas linhagens comerciais Cobb $^{\circledR}$ e Avian ${ }^{\circledR}$. Cada lote estudado continha 124.416 ovos. $\mathrm{O}$ acompanhamento das duas linhagens foi feito em três lotes, quando também foram coletados os seguintes dados de perdas: número de ovos inférteis; mortalidade embrionária até 7 dias de incubação; mortalidade embrionária de 8 a 14 dias de incubação; mortalidade embrionária de 15 a 18 dias de incubação; mortalidade embrionária de 19 a 21 dias de incubação; bicados vivos; bicados mortos; ovos trincados; ovos podres; ovos contaminados; caixa craniana aberta; anormal; má posição; problema de pernas; problemas de olho ou bico; vísceras expostas e nanismo.

TABELA 3. Organização das coletas realizadas no incubatório para acompanhamento dos lotes. Collect organization made in the incubator to monitor the batches.

\begin{tabular}{|c|c|c|}
\hline Dia de Coleta & Local de Amostragem & Variáveis Coletadas \\
\hline $4^{\underline{0}}$ dia de incubação & Sala de incubação/incubadora & $\begin{array}{l}\text { T; UR; VA; concentração de } \mathrm{CO}_{2} \\
\text { UFC de fungos }\end{array}$ \\
\hline $12^{-}$dia de incubação & Sala de incubação/incubadora & $\begin{array}{l}\text { T; UR; VA; concentração de } \mathrm{CO}_{2} \\
\text { UFC de fungos }\end{array}$ \\
\hline $16^{-}$dia de incubação & Sala de incubação/incubadora & $\begin{array}{l}\text { T; UR; VA; concentração de } \mathrm{CO}_{2} \\
\text { UFC de fungos }\end{array}$ \\
\hline $18^{\underline{0}}$ dia de incubação & \multicolumn{2}{|c|}{ Transferência dos ovos para nascedouro } \\
\hline $20^{\circ}$ dia incubação & Sala de nascedouros/nascedouro & $\begin{array}{l}\text { T; UR; VA; concentração de } \mathrm{CO}_{2} \\
\text { UFC de fungos }\end{array}$ \\
\hline $21^{0}$ dia de incubação & \multicolumn{2}{|c|}{ Nascimento } \\
\hline Vacinação & Sala de vacinação & $\begin{array}{l}\text { T; UR; VA; concentração de } \mathrm{CO}_{2} \\
\text { UFC de fungos }\end{array}$ \\
\hline
\end{tabular}

A análise de componentes principais foi empregada com o objetivo de associar as variáveis, observando o ângulo e a magnitude dos vetores. Vetores com pequena magnitude (68\%) não foram levados em consideração nas análises Vetores com direção e sentido semelhantes, considerados como fortemente associados positivamente e vetores possuindo direções semelhantes, mas sentidos diferentes implicavam associações negativas fortes. Vetores que formavam ângulos próximos a $90^{\circ}$ não foram considerados correlatos.

Após a coleta em três lotes, a análise estatística dos dados de ambiente e produção foi realizada utilizando MINITAB (2006).

\section{RESULTADOS E DISCUSSÃO}

Os resultados (Tabela 4) mostram que a linhagem comercial $\mathrm{Cobb}^{\circledR}$ apresentou melhores índices em todos os itens medidos, sendo que o peso médio dos ovos incubados se manteve igual àquele da linhagem Avian $^{\circledR}$. Os principais fatores que influenciam no peso do pintinho ao nascer são o peso do ovo, que é influenciado pela linhagem e pela idade da matriz e a perda de peso durante a incubação, esta primordialmente determinada pela porosidade da casca, umidade e temperatura de incubação. Ao nascer, o peso do pintinho representa aproximadamente 60 a $70 \%$ do peso do ovo no início da incubação (SOUZA, 2005). 
TABELA 4. Índices zootécnicos de três lotes estudados com duas linhagens comerciais. Indexes of three batches studied in two commercial strains.

\begin{tabular}{lcccccccc}
\hline \multirow{2}{*}{ Índices } & \multicolumn{3}{c}{ Lote 1 } & \multicolumn{2}{c}{ Lote 2 } & \multicolumn{2}{c}{ Lote 3 $^{\text {Média }}$} \\
\cline { 2 - 9 } Cobb $^{\circledR}$ & Avian $^{\circledR}$ & Cobb $^{\circledR}$ & Avian $^{\circledR}$ & Cobb $^{\circledR}$ & Avian $^{\circledR}$ & Cobb $^{\circledR}$ & Avian $^{\circledR}$ \\
\hline Ovos incubados & 7.680 & 13.056 & 13.824 & 6.912 & 13.824 & 6.912 & $11.776,0 \mathrm{a}$ & $8.960,0 \mathrm{~b}$ \\
Peso médio dos ovos & 69,5 & 70 & 69 & 69,7 & 69 & 69,7 & 69,2 & 69,8 \\
incubados (g) & 6.579 & 10.589 & 11.833 & 5.457 & 11.833 & 5.457 & $10.081,7 \mathrm{a}$ & $7.167,7 \mathrm{~b}$ \\
$\begin{array}{l}\text { Eclosão } \\
\text { Mortos/Refugo }\end{array}$ & 131 & 160 & 259 & 181 & 259 & 181 & $216,3 \mathrm{a}$ & $174,0 \mathrm{~b}$ \\
$\begin{array}{l}\text { Pintos de primeira } \\
\text { qualidade }\end{array}$ & 6.400 & 10.400 & 11.500 & 5.200 & 11.500 & 5.200 & $9.800 \mathrm{a}$ & $6.933,3 \mathrm{~b}$ \\
$\begin{array}{l}\text { Pintos de segunda } \\
\text { qualidade }\end{array}$ & 48 & 29 & 74 & 76 & 74 & 76 & $65,3 \mathrm{a}$ & $60,3 \mathrm{~b}$ \\
\hline
\end{tabular}

$\mathrm{a}, \mathrm{b}$ - resultados que divergiram com P-valor $\leq 0,01$, para o teste $\mathrm{t}$ de Student.

Os dados de quebra dos ovos do primeiro ao terceiro lotes monitorados (Tabela 5) foram coletados a partir dos dados de peso $(38-45 \mathrm{~g})$ e demais aspectos físicos dos pintinhos, como: apresentar respostas aos estímulos externos, ser uniforme e compatível com a linhagem e a idade do lote da matriz, ter abdômen firme e umbigo bem cicatrizado (GONZALES \& CAFÉ, 2003). De acordo com os autores, avaliam-se também defeitos físicos (pernas, tarsos, dedos e olhos), aparência da cloaca e estado de hidratação.

Os resultados indicaram diferença na mortalidade (8-14 dias), número de bicados vivos e incidência de má posição, em que a linhagem Avian ${ }^{\circledR}$ apresentou um número maior (P-valor=0,08; $\mathrm{P}$-valor $=0,05$ e $\mathrm{P}$-valor $=0,0009$, respectivamente). Já a linhagem $\mathrm{Cobb}^{\circledR}$ apresentou maior incidência de problemas de pernas ( $\mathrm{P}$-valor $=0,05)$.

TABELA 5. Resultados da perda após quebra de ovos realizada em três lotes monitorados, em duas linhagens distintas. Loss results after breaking eggs realized in three batches monitored in two distinct strains.

\begin{tabular}{|c|c|c|c|c|c|c|c|c|}
\hline \multirow[b]{2}{*}{ Incidências } & \multicolumn{2}{|c|}{ Lote 1} & \multicolumn{2}{|c|}{ Lote 2} & \multicolumn{2}{|c|}{ Lote 3} & \multicolumn{2}{|c|}{ Média } \\
\hline & $\begin{array}{c}\text { Cobb }^{\circledR} \\
\%\end{array}$ & $\begin{array}{c}\text { Avian }^{\circledR} \\
\%\end{array}$ & $\begin{array}{c}\mathrm{Cobb}^{\circledR} \\
\%\end{array}$ & $\begin{array}{c}\text { Avian }^{\circledR} \\
\%\end{array}$ & $\begin{array}{c}\mathrm{Cobb}^{\circledR} \\
\%\end{array}$ & $\begin{array}{c}\text { Avian }^{\circledR} \\
\%\end{array}$ & $\begin{array}{c}\mathrm{Cobb}^{\circledR} \\
\%\end{array}$ & $\begin{array}{c}\text { Avian }^{\circledR} \\
\%\end{array}$ \\
\hline Ovos inférteis & 0,20 & 0,22 & 0,47 & 1,02 & 0,18 & 0,33 & 36 & 41 \\
\hline Mortalidade (0-7 dias) & 0,28 & 0,19 & 0,29 & 0,46 & 0,13 & 0,21 & 82 & 72 \\
\hline Mortalidade (8-14 dias) & 0,01 & 0,02 & 0 & 0,11 & 0,036 & 0,043 & $6^{* *}$ & $14^{*}$ \\
\hline Mortalidade (15 -18 dias) & 0,07 & 0,06 & 0,08 & 0,08 & 0,05 & 0,1 & 25 & 21 \\
\hline Mortalidade (19-21 dias) & 0,03 & 0,03 & 0,065 & 0,07 & 0,043 & 0,13 & 18 & 19 \\
\hline Bicados vivos & 0,06 & 0,09 & 0,028 & 0,05 & 0,007 & 0,02 & $10 \mathrm{~B}$ & $18 \mathrm{~A}$ \\
\hline Bicados mortos & 0,03 & 0,015 & 0,02 & 0,08 & & 0,02 & 6 & 10 \\
\hline Ovos trincados & 0,02 & 0 & 0,05 & 0,008 & 0,007 & 0,043 & 10 & 9 \\
\hline Ovos podres & 0,01 & 0 & 0,007 & 0,02 & 0,007 & 0,02 & 3 & 4 \\
\hline Ovos contaminados & 0 & 0 & 0,001 & 0,04 & 0,014 & 0,02 & 4 & 5 \\
\hline Caixa craniana aberta & 0 & 0 & 0 & 0,02 & 0 & 0 & 0 & 2 \\
\hline Anormal & 0,01 & 0 & 0 & 0,04 & 0 & 0 & 1 & 3 \\
\hline Má posição & 0,01 & 3 & 0,001 & 0,04 & 0,014 & 3 & $5 b$ & $10 \mathrm{a}$ \\
\hline Problema de pernas & 0 & 0 & 0,007 & 0 & 0 & 0 & $1 \mathrm{~A}$ & OB \\
\hline Problemas de olho ou bico & 0 & 1 & 0 & 0 & 0 & 0 & 0 & 1 \\
\hline Vísceras & 0 & 0 & 2 & 0 & 0 & 2 & 2 & 2 \\
\hline Nanismo & 0 & 0 & 0 & 1 & 0 & 0 & 0 & 1 \\
\hline
\end{tabular}

*,** - resultados que divergiram com P-valor $=0,08 ; \mathrm{A}, \mathrm{B}$ - resultados que divergiram com P-valor $\leq 0,05$; a,b - resultados que divergiram com $\mathrm{P}$-valor $\leq 0,01$. 
Devido à necessidade de manutenção de padrões de eclosão de diferentes linhagens de frangos de corte existentes atualmente, os parâmetros ambientais devem ser ideais para sustentar o desenvolvimento embrionário (BOLELI, 2003; MURAROLI \& MENDES, 2003; BOERJAN, 2006). Isso demonstra que, para o alcance de melhores resultados de produção no incubatório, existe demanda de programas de incubação específicos para cada linhagem, em que a temperatura de casca de ovo pode ser usada como parâmetro para ajustes de temperatura de incubação (PAS REFORM, 2004).

De acordo com estudos realizados, a temperatura ótima de incubação pode variar não somente entre linhagens, mas também entre ovos de diferentes tamanhos (DECUYPERE, 1994; CHRISTENSEN et al., 1994; FRENCH, 1994).

\section{Associação das variáveis ambientais com os índices zootécnicos - Cobb ${ }^{\circledR}$}

De acordo com o gráfico de componentes principais (

FIGURA 1), foram classificadas as variáveis que estão associadas positiva e negativamente ao número de ovos eclodidos (Eclodidos) e à qualidade do produto final (pintos de primeira). As variáveis que refletem os índices produtivos estão praticamente em posição horizontal, paralelo ao eixo da primeira componente, isto é, esta componente resume a produtividade. Desse modo, a primeira componente foi nomeada de índice de perdas produtivas; pois, quando existem grandes magnitudes das projeções de vetores, no sentido positivo desta componente, obtêm-se índices ruins de produtividade (pintos de segunda, mortalidade e refugos). Por outro lado, quando os índices são bons (pintos de primeira), as magnitudes dos vetores projetam-se no sentido negativo.

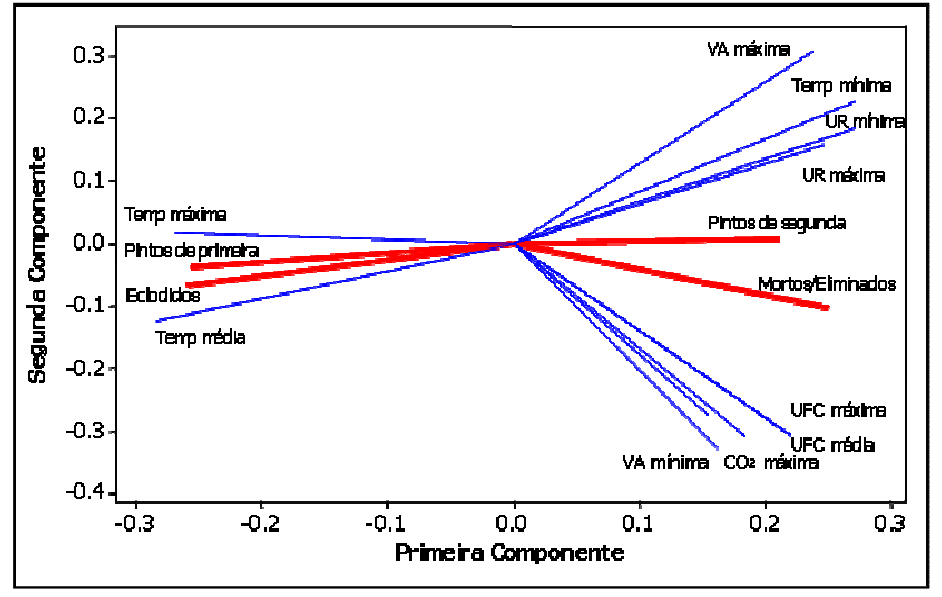

FIGURA 1. Gráfico de componentes principais para a correlação dos parâmetros ambientais na incubação e dados produtivos correspondentes à linhagem $\mathrm{Cobb}^{\circledR}$. Graphic correlation of main components for the environmental parameters in the incubation and productive data corresponding to Cobb ${ }^{\circledR}$ strain.

As variáveis ambientais podem ser divididas em três grupos distintos:

1. O primeiro grupo relaciona-se positivamente com a produtividade (eclosão e pintos de primeira), representada basicamente pela temperatura no interior das máquinas de incubação e nascedouro. Com esta classificação, constatou-se que as variáveis "temperatura máxima (Temp Máx )e "temperatura média (T média) possuem forte relação direta com as variáveis que refletem o desempenho favorável na produção. Ou seja, quanto mais alta a temperatura, maior e melhor a produtividade. $\mathrm{O}$ fato de a produtividade estar crescendo e melhorando com o aumento da temperatura máxima, sugere que a temperatura ideal, que maximiza a produtividade (tanto em qualidade como em quantidade), seria mais elevada do que aquela que se utiliza como referência atualmente. Isto é, as evidências sugerem um aumento na temperatura de referência do termostato, desde que haja um controle na variabilidade da temperatura. 
2. O segundo grupo, de maneira geral, associou-se negativamente aos pintos de primeira e pintos eclodidos e, portanto, a uma boa eclodibilidade. Este grupo correspondeu às variáveis de umidade relativa e velocidade do ar, associando-se positivamente ao aumento dos pintos de segunda.

3. O terceiro grupo foi compreendido pela concentração do dióxido de carbono $\left(\mathrm{CO}_{2}\right)$ e pela incidência de fungos, principalmente, e está associado positivamente à mortalidade e a refugos.

\section{Associação entre as quebras de ovos com o ambiente de incubação - COBB®}

O gráfico de componentes principais (FIGURA 2) mostra que a velocidade do ar máxima e velocidade do ar média possuem correlação positiva com a incidência de pintos bicados/vivos e bicados/mortos. Ou seja, com o aumento da velocidade do ar na incubação, maior é a incidência de embriões bicados/mortos e bicados/vivos. Entretanto, verifica-se que o aumento da velocidade mínima do ar e da média da umidade relativa está relacionado à diminuição da ocorrência de embriões bicados/mortos.

$\mathrm{O}$ aumento da concentração de dióxido de carbono está associado à diminuição da incidência de bicados/vivos, o que indica que a concentração de $\mathrm{CO}_{2}$ se manteve baixa, provavelmente devido à alta taxa de renovação do ar no equipamento, indicado pelos valores de velocidade do ar. A incidência de embriões com vísceras expostas e má-formação das pernas teve relação positiva com o aumento da temperatura mínima, e forte relação negativa com o aumento da temperatura máxima de incubação.

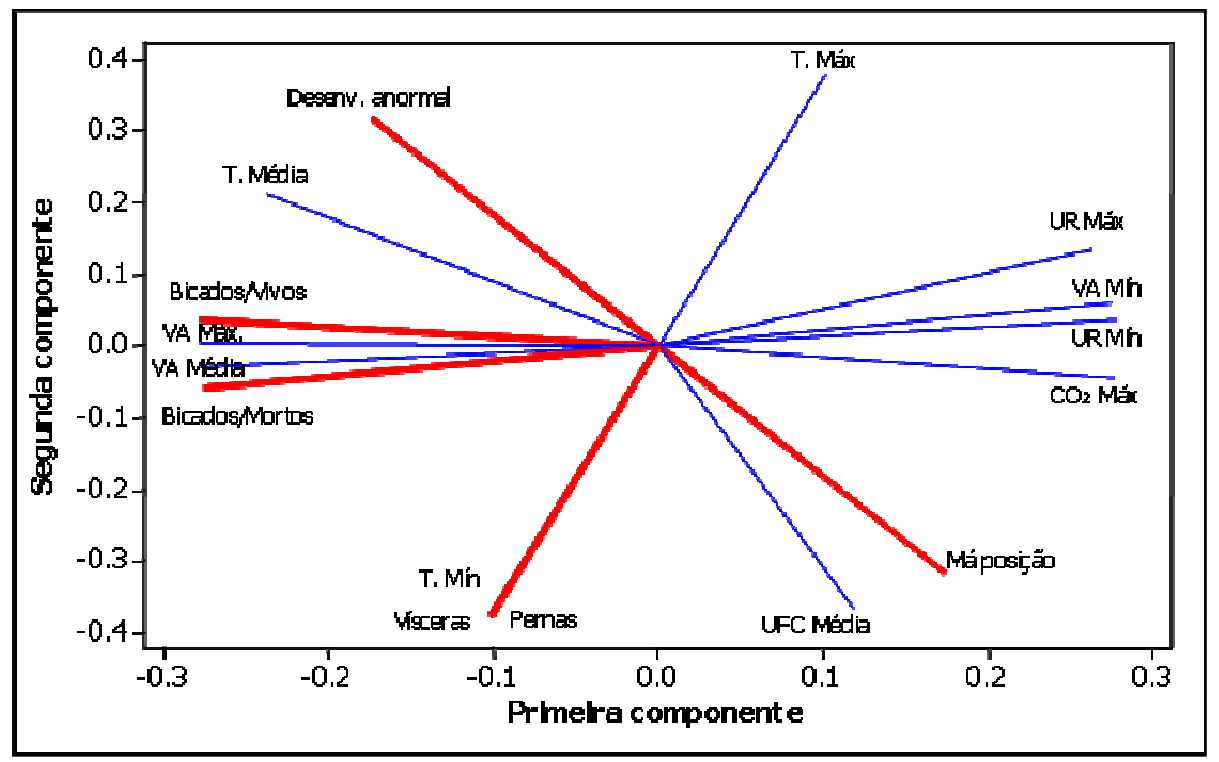

FIGURA 2. Correlação dos resultados da quebra de ovos com o ambiente de incubação correspondente à linhagem $\mathrm{Cobb}^{\circledR}$. Correlation of the results of broken eggs in the incubation environment corresponding to $\mathrm{Cobb}^{\circledR}$ strain.

Com a diminuição da amplitude térmica de incubação, foi maior a incidência de embriões com vísceras expostas e má-formação nas pernas. A diminuição da amplitude térmica tende a provocar aumento da ocorrência dessas anormalidades, provavelmente por esta amplitude reduzida de dados de temperatura estar em níveis inferiores da temperatura desejada para ótima incubação, como constatado no gráfico, tanto no interior da incubadora, quanto no interior do nascedouro. Isto deixa claro que, no interior das máquinas de incubação, as temperaturas encontradas foram consideradas baixas, seja de acordo com os dados recomendados pela literatura, seja devido à alta taxa de renovação de ar. Isso afetou o desenvolvimento embrionário dessa linhagem, acarretando o aparecimento de anormalidades e interferindo diretamente no sucesso da incubação (WILSON, 1991; BOLELI, 2003). 
Quanto à incidência de fungos, verificou-se associação positiva entre essa variável e a má posição do embrião, sugerindo que o número de UFC de fungos é a causa desse tipo de anormalidade e de queda na eficiência produtiva. $\mathrm{O}$ gráfico de componentes principais apontou a correlação do ambiente de incubação, durante a primeira etapa deste processo, com a mortalidade embrionária (FIGURA 3). Foi verificada forte associação da mortalidade embrionária de 0 a 7 dias de incubação com a contaminação por fungos. Dentre os gêneros identificados na incubadora, destaca--se Penicillium, gênero responsável por mortalidade embrionária e baixa eclodibilidade (LIMA et al., 2001). Estes gêneros de fungos podem ser introduzidos nos incubatórios, inicialmente, através dos ovos contaminados, insetos ou por armazenamento inadequado dos ovos, podendo disseminar-se rapidamente para todo o ambiente, se não houver um programa de desinfecção adequado (OUCKAMA, 1996). Além disso, verificou-se, nesse período, associação negativa com a temperatura máxima, indicando novamente que a temperatura de incubação deve ser elevada.

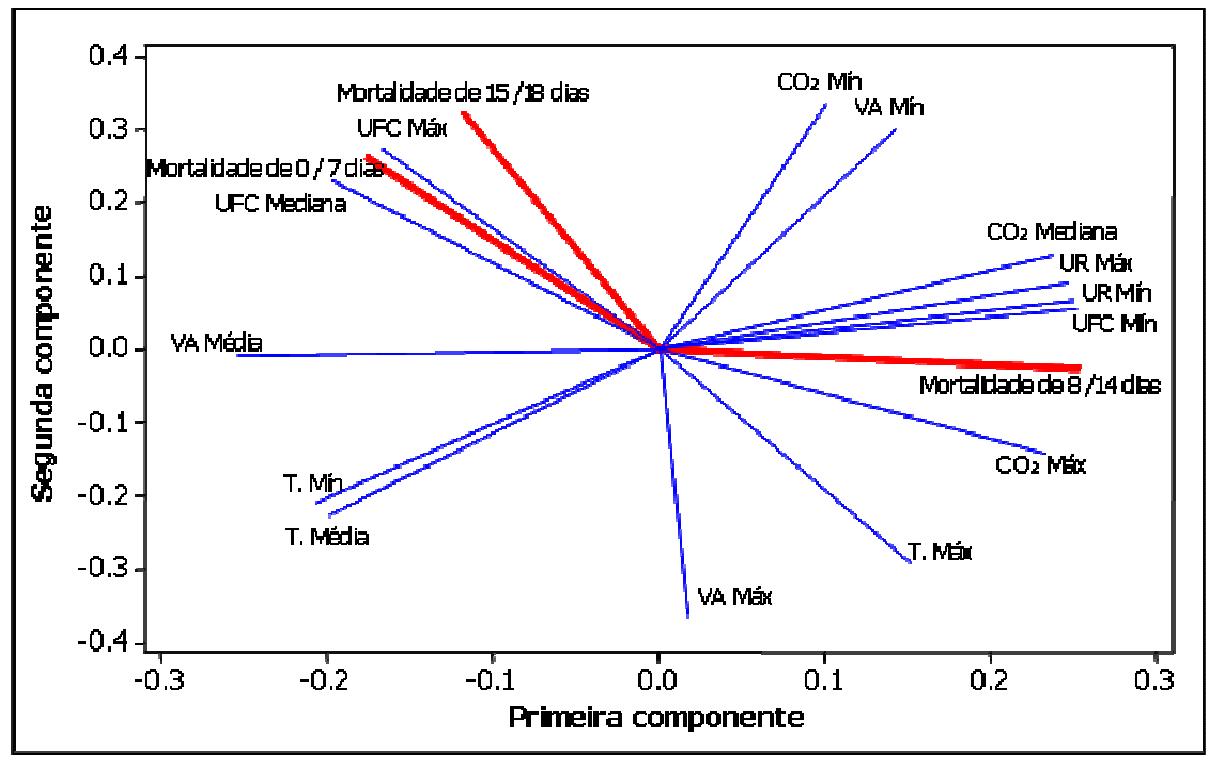

FIGURA 3. Correlação do ambiente de incubação na fase de incubadora e mortalidade embrionária correspondentes à linhagem $\mathrm{Cobb}^{\circledR}$. Correlation of the incubation environment in the incubator stage and embryo mortality corresponding to $\mathrm{Cobb}^{\circledR}$ strain.

A mortalidade embrionária, de 8 e 14 dias de incubação (Figura 4), apresentou associação positiva com a umidade relativa e com a concentração de dióxido de carbono, indicando que, com o aumento dessas variáveis, nesta fase de incubação, pode ocorrer mortalidade. Também foi verificada correlação negativa dos valores médios da velocidade do ar com a mortalidade, nesta etapa de incubação; ou seja, com a diminuição da velocidade do ar, deve haver maior ocorrência de mortalidade embrionária, entre 8-14 dias de incubação. A ocorrência da mortalidade embrionária entre 15 e 18 dias de incubação está positivamente associada à incidência de fungos e negativamente associada à temperatura. Estes resultados sugerem que a temperatura deve ser aumentada, bem como os padrões sanitários da máquina de incubação precisam ser melhorados.

Os dados, quando comparados com os padrões de Sadler (DI FABIO, 1990), apontam que este local apresenta classificação mediana, quanto à qualidade sanitária e ligeiramente abaixo da média, quando se leva em consideração o corredor da sala de incubação, sugerindo que o controle sanitário deve ser rígido em todas as suas dependências. PETINE (1990) e TESSARI et al. (2002) relataram que a biosseguridade de um incubatório é fundamental para o desempenho zootécnico dos pintos de corte.

A correlação dos dados ambientais com a mortalidade desta linhagem no nascedouro, apontada no gráfico de componentes principais (Figura 4), mostra que a mortalidade embrionária 
apresentou relação negativa com a mediana da temperatura e com a mínima velocidade do ar, sugerindo que a temperatura deve ser aumentada, visando à melhoria nos índices de produção.

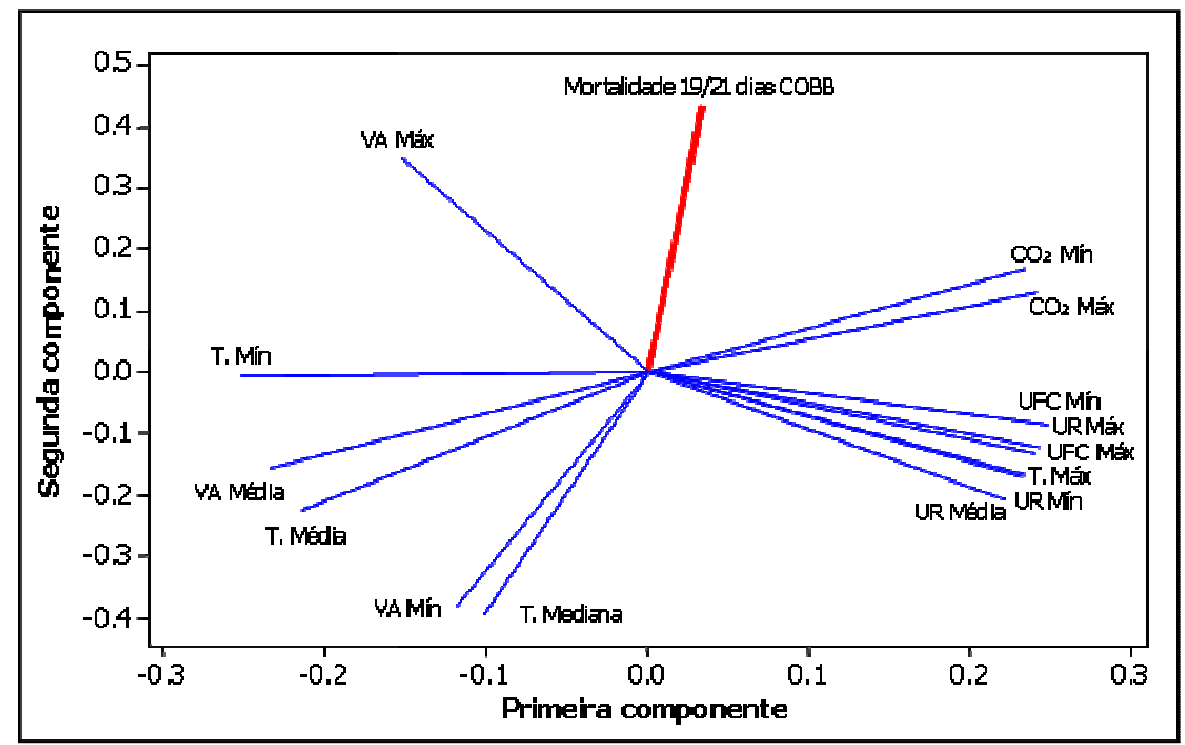

FIGURA 4. Correlação do ambiente na fase de nascedouro com mortalidade embrionária correspondentes à linhagem $\mathrm{Cobb}^{\circledR}$. Correlation of the environment in the birth stage with embryonic mortality corresponding to $\mathrm{Cobb}^{\circledR}$ strain.

\section{Correlação das variáveis ambientais com os índices zootécnicos - Avian®}

O gráfico de componentes principais (FIGURA 5) mostra que a segunda componente é a que possui mais informações sobre as variáveis de produção. Entretanto, pôde-se verificar que, assim como na linhagem $\mathrm{Cobb}^{\circledR}$, a temperatura foi apontada como variável fundamental para a obtenção de bons índices produtivos e poderia ser ligeiramente aumentada e estabilizada, para melhores condições de incubação ao embrião.

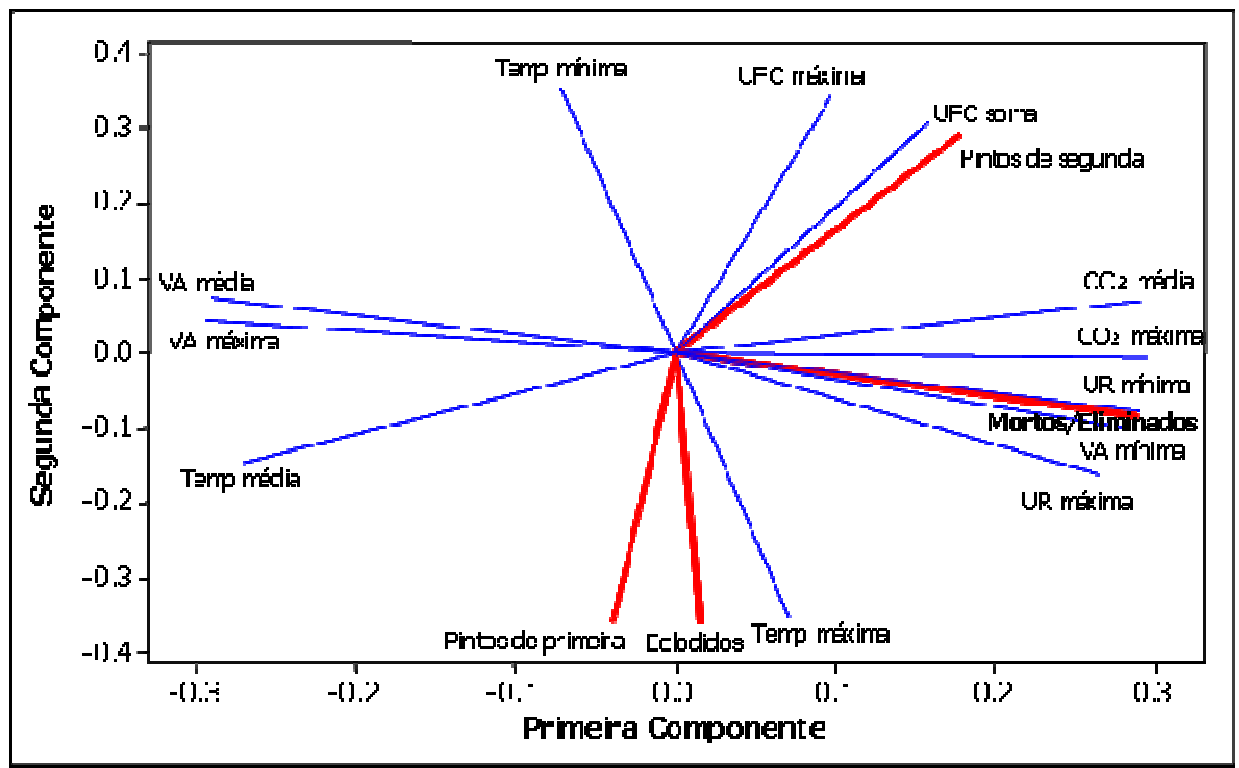

FIGURA 5. Gráfico de componentes principais para correlação dos parâmetros ambientais na incubação e dados produtivos correspondentes à linhagem Avian ${ }^{\circledR}$. Graphic correlation of main components for the environmental parameters in the incubation and productive data corresponding to Avian ${ }^{\circledR}$ strain. 
Com respeito à incidência de pintos de corte de segunda qualidade, esta tende a aumentar com o aumento de UFC de fungos. Sendo, portanto, o número de UFC de fungos forte indicador ambiental relacionado à diminuição da qualidade do pintinho, podendo-se estabelecer relação negativa desta variável com a qualidade do pintinho e eclodibilidade. Quanto à mortalidade embrionária e refugagem, encontrou-se forte associação positiva com o aumento da umidade relativa, bem como aumento da concentração de dióxido de carbono. $\mathrm{O}$ aumento da velocidade do ar e da temperatura associou-se à redução de mortalidade.

\section{Correlação das análises de quebra de ovo com o ambiente de incubação - AVIAN ${ }^{\circledR}$}

De acordo com o gráfico de componentes principais (FIGURA 6), verificou-se que há também, para essa linhagem, forte associação do aumento da temperatura mínima com o aumento da incidência de anormalidades apresentadas por aves recém-eclodidas, tais como incidência de caixa craniana aberta e má posição do embrião. Sugere-se, neste caso, aumento da temperatura máxima de incubação, uma vez que esta variável se relaciona negativamente a estes índices. Esta recomendação está fundamentada no fato de que as temperaturas amostradas neste estudo se encontraram abaixo do que é preconizado pela literatura (FRENCH, 1997). Também com relação às temperaturas no nascedouro, 90\% destas mantiveram-se abaixo da faixa de temperatura recomendada para obtenção de bons resultados na incubação (MAULDIN, 2001).

O gráfico também mostra que a incidência de pintinhos com vísceras expostas está associada positivamente ao aumento da velocidade mínima, à diminuição da velocidade máxima do ar e à umidade relativa mínima. Isso sugere que os valores de velocidade do ar sejam deslocados para níveis superiores. $\mathrm{O}$ aumento de incidência fúngica, por sua vez, pode estar vinculado ao acréscimo da umidade relativa. O gráfico de componentes principais (FIGURA 7) aponta a correlação do ambiente de incubação na fase de incubadora, com os resultados de mortalidade obtidos na quebra de ovos.

A velocidade do ar associou-se positivamente à mortalidade de 0-7 dias de incubação, indicando que o aumento da velocidade do ar provocou aumento da mortalidade, o que pode estar vinculado às baixas temperaturas encontradas no interior da incubadora neste período e, por sua vez, podendo interferir no desenvolvimento do embrião, conforme sugere BOERJAN (2006).

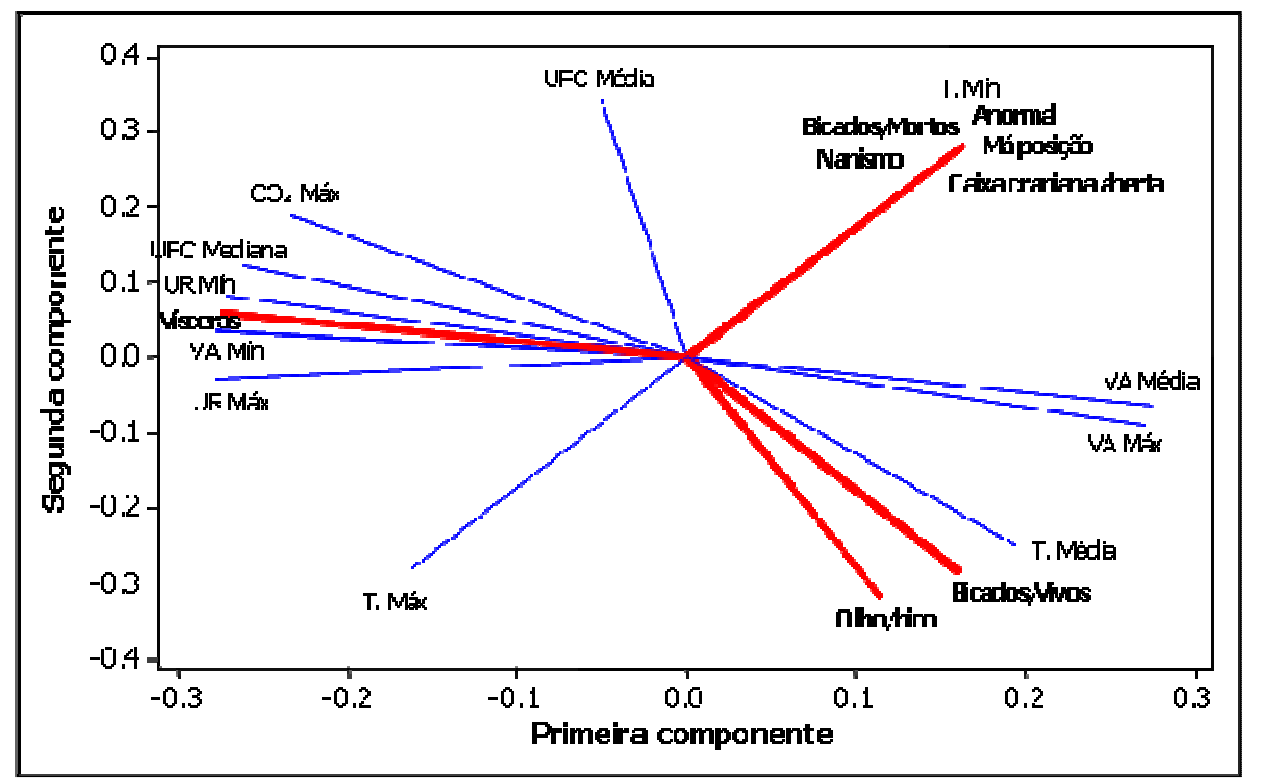

FIGURA 6. Correlação da análise de quebra de ovos com o ambiente de incubação para a linhagem Avian ${ }^{\circledR}$. Correlation analysis of broken eggs in the incubation environment for Avian ${ }^{\circledR}$ strain. 


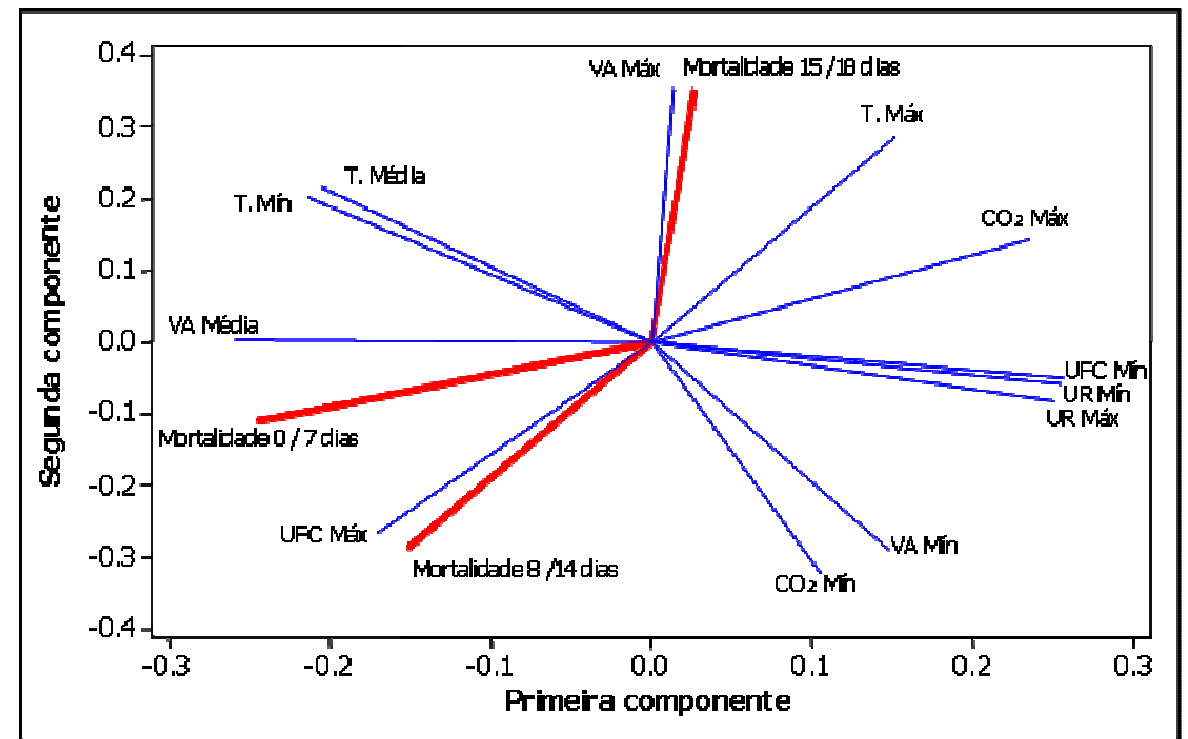

FIGURA 7. Correlação do ambiente de incubação na fase de incubadora com mortalidade embrionária para a linhagem Avian ${ }^{\circledR}$. Correlation of the incubation environment in the incubator stage with embryo mortality for Avian ${ }^{\circledR}$ strain.

A mortalidade de 8-14 dias de incubação esteve associada positivamente à incidência de fungos na incubadora. Houve alta concentração de fungos do gênero Penicillium e Aspergillus, apontados como principais gêneros relacionados às perdas produtivas em incubatório (RICHARD, 1997; TESSARI et al., 2002). O gráfico mostrou, também, que o aumento do vetor que representa a temperatura, está relacionado com a diminuição da mortalidade neste período.

A mortalidade de 15-18 dias de incubação apresentou associação positiva com a velocidade máxima do ar.

No nascedouro, a mortalidade de embriões entre 19-21 dias de incubação relacionou-se positivamente à incidência de fungos (FIGURA 8). Neste local, observou-se incidência crítica de UFC de fungos quando comparados com os padrões recomendados (DI FABIO, 1990), o que promove mortalidade embrionária.

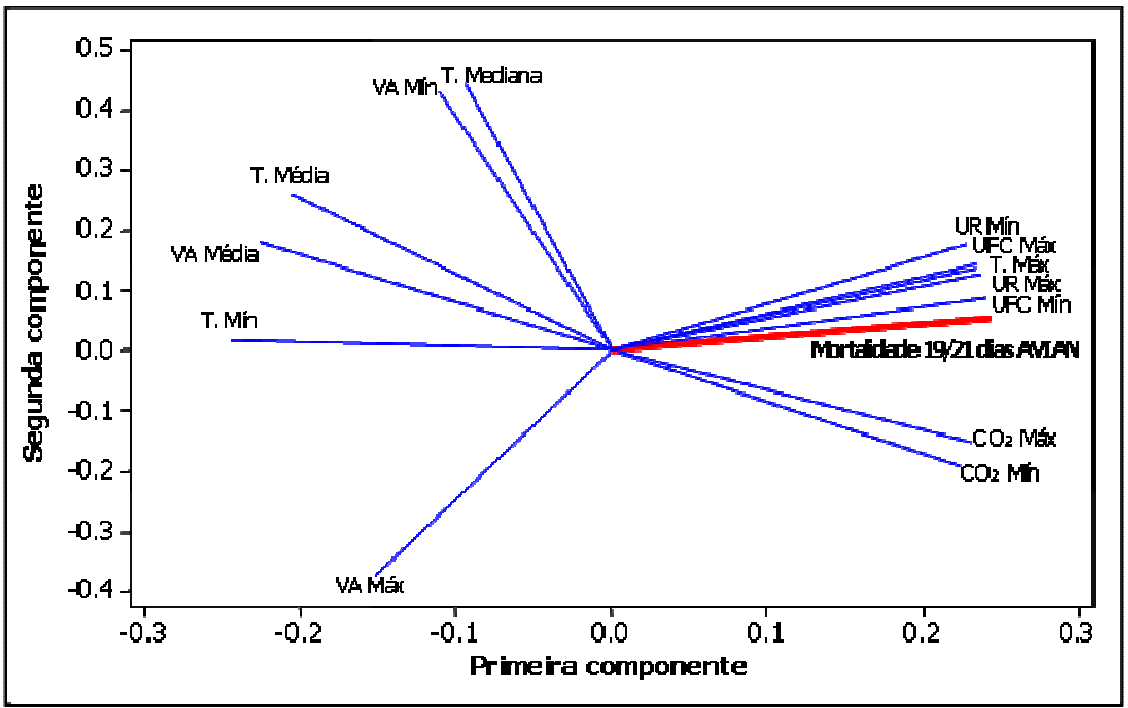

FIGURA 8. Correlação do ambiente de incubação na fase de nascedouro com a mortalidade embrionária para a linhagem Avian ${ }^{\circledR}$. Correlation of the incubation environment in the birth stage with embryonic mortality for Avian $^{\circledR}$ strain. 
Ainda, neste local, houve alta incidência de Aspergillus fumigatus, agente micótico importante na atividade avícola devido ao impacto negativo na produção (CERVANTES, 1995; BRAEM, 1988). BARNES \& GROSS (1997) observaram que infecção provocada por fungos do gênero Aspergillus causaram alta mortalidade em pintinhos entre o primeiro e o terceiro dia de idade, sendo tal contaminação oriunda de nascedouros contaminados. Além disso, estes gêneros são os principais produtores de micotoxinas, quando estas são submetidas a determinadas condições favoráveis ao seu desenvolvimento (LIMA et al., 2004).

Fungos são responsáveis por morte embrionária e também por aspergilose, que pode afetar o sistema respiratório das aves, levando à mortalidade do embrião e das aves jovens, acometendo os pulmões e os sacos aéreos das aves, quando ocorre a inalação dos esporos fúngicos que se dispersam pelo ar por serem extremamente leves (ROSSINI \& MONTEIRO, 2004).

Observou-se também a associação negativa da temperatura com a mortalidade no nascedouro. O gráfico permite afirmar que o aumento da umidade relativa associou-se ao aumento da mortalidade, como indicou BOLELI (2003), sugerindo que esta linhagem foi sensível aos valores de umidade relativa amostrados, quando valores próximos de $90 \%$ de umidade relativa foram encontrados no nascedouro.

\section{Comparação das respostas das linhagens avaliadas ao ambiente de incubação}

Os resultados encontrados, quanto à influência do ambiente de incubação sobre o desempenho das duas linhagens de frango de corte, levando em consideração a análise de componentes principais, mostram que houve diferença entre os desempenhos das linhagens (TABELA 6). Ambas as linhagens estudadas tiveram perdas produtivas relacionadas à baixa temperatura ambiente na incubadora e no nascedouro, reforçando a ideia de que a temperatura de incubação é o fator mais importante para que sejam alcançados índices produtivos ideais.

TABELA 6. Resumo da influência do ambiente de incubação sobre o desempenho de duas linhagens de frango de corte. Summary table of the influence of incubation environment on the performance of two strains of broiler chicken.

\begin{tabular}{|c|c|c|}
\hline Índices Produtivos & $\mathrm{Cobb}^{\circledR}$ & Avian $^{(}$ \\
\hline $\begin{array}{l}\text { Queda na eclodibilidade e } \\
\text { qualidade de pintinho }\end{array}$ & $\begin{array}{l}\text { Alta velocidade do ar } \\
\text { Alta umidade relativa } \\
\text { Alta contaminação por fungos } \\
\text { Alta concentração de } \mathrm{CO}_{2} \\
\text { Baixa temperatura }\end{array}$ & $\begin{array}{l}\text { Baixa velocidade do ar } \\
\text { Alta umidade relativa } \\
\text { Alta contaminação por fungos } \\
\text { Alta concentração de } \mathrm{CO}_{2} \\
\text { Baixa temperatura }\end{array}$ \\
\hline $\begin{array}{l}\text { Incidência de pintinhos } \\
\text { Bicados/Mortos e Bicados/Vivo }\end{array}$ & $\begin{array}{l}\text { Alta velocidade do ar } \\
\text { Baixa concentração de } \mathrm{CO}_{2}\end{array}$ & Baixa temperatura \\
\hline $\begin{array}{l}\text { Incidência de anormalidades e } \\
\text { má posição embrionária }\end{array}$ & $\begin{array}{l}\text { Baixa temperatura } \\
\text { Alta contaminação por fungos }\end{array}$ & $\begin{array}{l}\text { Baixa temperatura } \\
\text { Baixa velocidade do ar } \\
\text { Baixa umidade relativa }\end{array}$ \\
\hline Mortalidade entre $0 / 7$ dias & $\begin{array}{l}\text { Baixa temperatura } \\
\text { Alta contaminação por fungos }\end{array}$ & Alta velocidade do ar \\
\hline Mortalidade entre $8 / 14$ dias & $\begin{array}{l}\text { Alta umidade relativa } \\
\text { Alta concentração de } \mathrm{CO}_{2} \\
\text { Baixa velocidade do ar }\end{array}$ & Alta contaminação por fungos \\
\hline Mortalidade entre $15 / 18$ dias & $\begin{array}{l}\text { Baixa temperatura } \\
\text { Alta contaminação por fungos }\end{array}$ & Alta velocidade do ar \\
\hline Mortalidade entre 19/21 dias & Baixa temperatura & $\begin{array}{l}\text { Baixa temperatura } \\
\text { Alta contaminação por fungos } \\
\text { Alta umidade relativa }\end{array}$ \\
\hline
\end{tabular}


A alta umidade relativa, a concentração de dióxido de carbono e a concentração de fungos foram apontadas como variáveis relacionadas à queda nos padrões de eclodibilidade e na qualidade do pintinho, além de provocar aumento da mortalidade, principalmente em embriões da linhagem $\mathrm{Cobb}^{\circledR}$.

A literatura indica que embriões sob estresse devido à alta umidade relativa tendem a eclodir precocemente, sem alcançar, no entanto, o máximo de desenvolvimento (DECUYPERE et al., 2003). Exposição de embriões a concentrações altas de dióxido de carbono pode reduzir, em algumas fases de incubação, a taxa de eclosão (MAULDIN, 2001). Neste trabalho, a concentração de $\mathrm{CO}_{2}$ somente teve relação com a mortalidade embrionária entre oito e quatorze dias de incubação, para os embriões da linhagem $\mathrm{Cobb}^{\circledR}$.

A incidência de anormalidades manteve-se vinculada à baixa temperatura de incubação. No entanto, para embriões da linhagem $\mathrm{Cobb}^{\circledR}$, a incidência de anormalidades manteve-se altamente correlacionada à contaminação por fungos que, embora não tenha sido considerada alta quando comparada com os padrões preconizados (TESSARI et al., 2002), foi suficiente para impactar negativamente o volume e a qualidade de produção.

Embriões da linhagem Avian ${ }^{\circledR}$ tiveram associados ao aparecimento de anormalidades a velocidade baixa do ar, o que pode ter levado ao aumento na concentração de dióxido de carbono, que está relacionado com a variação na eclodibilidade. A incidência de anormalidades para esta linhagem manteve-se relacionada à baixa umidade relativa, causa conhecida de falta de sustentação nas patas dos pintos de corte (BOLELI, 2003).

\section{CONCLUSÕES}

A queda na eclodibilidade de pintos de corte, de ambas as linhagens, foram influenciadas pelas condições ambientais (baixa velocidade do ar, alta umidade relativa, alta contaminação por fungos, alta concentração de $\mathrm{CO}_{2}$ e baixa temperatura) tanto do incubatório, como no nascedouro.

A incidência de pintinhos bicados mortos ou vivos nas linhagens foi influenciada diferentemente pela alta velocidade do ar e a baixa concentração de $\mathrm{CO}_{2}$, que afetaram negativamente as aves de linhagem $\mathrm{Cobb}^{\circledR}$; enquanto a baixa temperatura foi a variável que mais impactou nesse resultado das aves da linhagem Avian ${ }^{\circledR}$. Quanto à incidência de anormalidades e má posição embrionária, a linhagem $\mathrm{Cobb}^{\circledR}$ apresentou maior resposta à baixa temperatura e alta contaminação por fungos, enquanto a linhagem Avian ${ }^{\circledR}$ teve impacto nos resultados quando exposta a baixos valores de temperatura, umidade relativa e velocidade de ar.

A temperatura ambiente baixa foi, de maneira geral, a maior causa de mortalidade nas aves da linhagem $\mathrm{Cobb}^{\circledR}$, nas várias idades do embrião, enquanto as aves da linhagem Avian ${ }^{\circledR}$ apresentaram maior mortalidade em função da alteração da velocidade do ar. As duas linhagens também apresentaram aumento da mortalidade com o acréscimo da incidência de fungos no incubatório.

\section{AGRADECIMENTOS}

À FAPESP e ao CNPq, pelo auxílio à pesquisa e bolsa.

\section{REFERÊNCIAS}

BARNES, H.J.; GROSS, W.B. Colibacilosis. In: CALNEK, B.W. Disease of poultry. $10^{\text {th }}$ ed. Ames: Iowa State University Press, 1997. p.131-141.

BIEZUS, A.J. Incubatório. 2001. Disponível em: <http://www.aviculturaindustrial.com.br/site/ dinamica.asp?id=1688\&tipo_tabela=produtos\&categoria=avicultura_postura $>$. Acesso em: 30 nov. 2005. 
BOERJAN, M.L. Incubação em estágio único para melhorar a uniformidade. In: CONFERÊNCIA APINCO 2006 DE CIÊNCIA E TECNOLOGIA AVÍCOLAS, 2006, Santos. Anais... Campinas: FACTA, 2006. v.1, p.325-333.

BOLELI, I.C. Estresse, mortalidade e malformações embrionárias. In: MACARI, M.;

GONZÁLES, E. Manejo da incubação. Campinas: Fundação APINCO de Ciência e Tecnologia Avícolas, 2003. p.472-498.

BRAEM, G. Limiting Aspergillus in the hatchery. International Hatchery Practice, Birmingham, v.2, n.8, p.11-13, 1988.

BRAMWELL, R.K. Egg shell mottling and hatchability, 2002. Disponível em: $<$ http://www.thepoultrysite.com/FeaturedArticle/FATopic.asp?AREA=Incubation\&Display=28>. Acesso em: 11 jul. 2006.

CALIL, T.A.C. Princípios básicos de incubação. In: CONFERÊNCIA APINCO 2007, SIMPÓSIO SOBRE INCUBAÇÃO, 2007. Santos. Anais... Campinas: Fundação APINCO de Ciência e Tecnologia Avícola, 2007. 1 CD-ROM.

CERVANTES, H. Evaluación y manejo de los problemas respiratórios en pollos de engorde. Avicultura Profesional, Santiago, v.13, n.2, p.74-84, 1995.

CHRISTENSEN, V.L.; DONALDSON, W.E.; NESTOR, K.E. Incubation temperature effects on metabolism and survival of turkey embryos. In: EUROPEAN POULTRY CONFERENCE, 9., 1994, Glasgow. Proceedings... Glasgow: World's Poultry Science Association, 1994. v.2, p.399402.

DECUYPERE, E. Incubation temperature and postnatal development. In: EUROPEAN POULTRY CONFERENCE, 9., 1994, Glasgow. Proceedings... Glasgow: World's Poultry Science Association, 1994. v.2, p.407-410.

DECUYPERE, E.; MALHEIROS, R.D.; MORAES, V.M.B.; BRUGGEMAN, V. Fisiologia do embrião. In: MACARI, M.; GONZÁLES, E. Manejo da incubação. Campinas: Fundação APINCO de Ciência e Tecnologia Avícolas, 2003. v.1, p.65-94.

DECUYPERE, E.; MICHELS, H. Incubation temperature as a management tool: a review. World's Poultry Science Journal, Ithaca, n.48, p.28-38, 1992.

DECUYPERE, E.; TONA, K.; BRUGGEMAN, V. World's Poultry Science Journal, Beekbergen, v.57, n.1, p.127-138, 2001.

DI FABIO, J. Higiene e controle de qualidade no incubatório. In: SILVA, E.N. Curso de atualização em incubação. Campinas: Arbor Acres Farm, 1990. p.51-60.

FRENCH, N.A. Do incubation temperature requirements vary between eggs? In: EUROPEAN POULTRY CONFERENCE, 9., 1994, Glasgow. Proceedings... Glasgow: World's Poultry Science Association, 1994. v.2, p.395-398.

FRENCH, N.A. Modeling incubation temperature: the effects of incubator design, embryonic development, and egg size. Poultry Science, Auburn, v.76, n.3, p.124-133, 1997.

GONZALES, E. Embriologia e desenvolvimento embrionário. In: MACARI, M.; GONZALES, E. Manejo da incubação. Campinas: FACTA, 2003. 537 p.

GONZALES, E.; CAFÉ, M.B. Produção de pintinhos com qualidade total. In: MACARI, M.; GONZÁLES, E. Manejo da incubação. Campinas: Fundação APINCO de Ciência e Tecnologia Avícolas, 2003. p.515-526.

GUSTIN, P.C. Biossegurança no incubatório. In: MACARI, M.; GONZÁLES, E. Manejo da incubação. Campinas: FACTA, 2003. p.297-352. 
LIMA, A.M.C.; NÄÄS, I.A.; BARACHO, M.S.; MIRAGLIOTTA, M.Y. Ambiência e bem-estar. In: MENDES, A.A.; NÄ̈̈S, I.A.; MACARI, M. Produção de frangos de corte. Campinas: FACTA, 2004, v.1, p. 38-46.

LIMA, J.S. Jr.; PINTO, D.M.; CARRASCO, L.O.; SALGUERO, F.J.B.; MEIRELES, M.C.A. Incidência de fungos na produção de pintos de corte de um dia de idade. Revista Brasileira de Agrociência, Pelotas, v.7, n.1, p.73-77, 2001.

MAULDIN, J.M. Factors affecting hatchability. In: BELL, D.D.; WEAVER, W.D. Commercial egg production. Norwill: Auburn Academic Publishers, 2001. p.727-773.

MINITAB. Statistical Software 15.1.0.0. State College: Minitab, 2006.

MURAROLI, A.; MENDES, A.A. Manejo da incubação, transferência e nascimento do pinto. In: MACARI, M.; GONZÁLES, E. Manejo da incubação. Campinas: FACTA, 2003. p.180-198.

OUCKAMA, R.M. Monitoria de incubatório através de resíduos de incubação. In:

INTERNATIONAL POULTRY CONSULTANTS. Clínica de incubação. Brasília: IPC, 1996. p.14.

PAS REFORM. Hatchery technologies. Hatchery for the future. 2004. Disponível em:

$<$ http://www.pasreform.com/downloads/Pasreform_Basics_artikelen.pdf>. Acesso em: 6 nov. 2007.

PETINE, A.J. Higiene e controle de qualidade no incubatório. In: SILVA, E.N. Curso de atualização em incubação. Campinas: Arbor Acres Farm, 1990. p.101-107.

PONTECORVO, G.; ROPER, J.A.; HEMMONS, D.W.; MACDONALD, K.D.; BUFTON, A.W. The genetics of Aspergillus nidulans. Advances in Genetics, Cambridge, v.5, p.141-238, 1953.

RICHARD, J.L. Aspergillosis. In: CALNEK, B.W. Disease of poultry. $10^{\text {th }}$ ed. Ames: Iowa State University Press, 1997. p.351-360.

ROSA, P.S.; ÁVILA, V.S. Variáveis relacionadas ao rendimento da incubação de ovos em matrizes de frangos de corte. Concórdia: EMBRAPA Suínos e Aves, 2000.

ROSSINI, L. I.; MONTEIRO, M.C.G.B. Problemas respiratórios em frangos de corte. In: MENDES, A.A.; NÄÄS, I.A.; MACARI, M. Produção de frangos de corte. Campinas: FACTA, 2004. v.1, p.261-272.

SOUZA, A.V.C. Fundamentos técnicos para utilização de dietas pós-eclosão para frangos de corte, 2005. Disponível em: <http://www.polinutri.com.br/ conteudo_artigos_anteriores_ abril05.htm>. Acesso em: 8 out. 2007.

TESSARI, E.N.C.; CARDOSO, A.L.S.P.; CASTRO, A.G.M.; KANASHIRO, A.M.I.; ZANATTA, G.F. Avaliação das condições sanitárias de incubatório de pintos de corte. Arquivo Instituto Biológico, São Paulo, v.69, n.3, p.1-4, 2002.

TONA, K.; BAMELIS, F.; DE KETELAERE, B.; BRUGGEMAN, V.; MORAES, V.M.B.; BUYSE, J.; ONAGBESAN, O.; DECUYPERE, E. Effects of egg storage time on spread of hatch, chick quality, and chick juvenile growth. Poultry Science, Auburn, v.82, n.2, p.736-741, 2003.

WILSON, H.R. Physiological requirements of the developing embryo: temperature and turning. In: TULLET, S.G. Avian incubation. Londres: Ed. Butterworth-Heinemann, 1991. Chapter. 9, p.145156. 